\title{
Reflexos de um processo de qualificação da Atenção Primária à Saúde na rotina e no cuidado produzido por seus trabalhadores
}

\author{
I ${ }^{1}$ Mariana Lectícia Beraldi, ${ }^{2}$ Fernanda de Freitas Mendonça, \\ ${ }^{3}$ Brigida Gimenez Carvalho, ${ }^{4}$ Sarah Beatriz Coceiro Meirelles Félix I
}

Resumo: Estudo qualitativo, exploratório, do tipo estudo de caso, que objetivou compreender os reflexos de um programa de qualificaçẫo da Atenção Primária à Saúde no processo de trabalho e no cuidado ofertado. A coleta de dados ocorreu de julho de 2018 a abril de 2019, utilizando observação-participante e entrevista semiestruturada com trabalhadores de uma Unidade de Saúde da Família. Os resultados apontaram a organização do processo de trabalho, sobrecarga física e mental dos profissionais, ênfase em questóes burocráticas em detrimento do cuidado e dificuldade do processo em contemplar as singularidades do território. Apesar disso, oportunizou a reflexão sobre a prática profissional. Processos verticalizados e descontextualizados dificultam a compreensão da realidade e, por isso, a importância de práticas de Educação Permanente em Saúde como espaços de diálogo e problematização sobre o vivido, de forma a adequar os processos da macropolítica à realidade local.

> Palavras-chave: Atenção Primária à Saúde; relações interprofissionais; avaliação em saúde; Educação Permanente em Saúde.

\author{
1 Saúde Coletiva, Universidade \\ Estadual de Londrina. Londrina-PR, \\ Brasil (mlberaldi@hotmail.com). \\ ORCID: 0000-0002-2730-7331 \\ 2 Saúde Coletiva, Universidade \\ Estadual de Londrina. Londrina-PR \\ Brasil (fernanda0683@gmail.com). \\ ORCID: 0000-0002-3532-5070 \\ ${ }^{3}$ Saúde Coletiva, Universidade \\ Estadual de Londrina. Londrina- \\ PR, Brasil (brigidagimenez@ \\ gmail.com). \\ ORCID: 0000-0002-1029-217X \\ ${ }^{4}$ Saúde Coletiva, Universidade \\ Estadual de Londrina. Londrina-PR, \\ Brasil (sbmeirelles@hotmail.com). \\ ORCID: 0000-0003-3850-870X
}

Recebido em: 15/05/2020 Aprovado em: 09/12/2020 Revisado em: 22/03/2021 


\section{Introdução}

A avaliação dos atributos da Atenção Primária à Saúde (APS) e a qualificação do trabalho em saúde mostram-se como um importante componente do processo de gestão (SILVA, 2014), que servem tanto para verificar como uma política está se desenvolvendo quanto para colocar em análise os processos de trabalho e orientar os trabalhadores no aprimoramento de suas ações (MALTA et al., 2016). Nesse sentido, no contexto nacional em 2011, houve a reformulação da Política Nacional de Atenção Básica (PNAB), a qual propôs o Programa de Melhoria do Acesso e da Qualidade (PMAQ) com o objetivo de ampliar o acesso e a melhoria da qualidade da APS por meio do repasse de recursos financeiros as equipes que obtivessem bons resultados no processo de avaliaçáo.

Já no contexto do Estado do Paraná, houve a implantação do Programa de Qualificação da APS (APSUS) (PARANÁ, 2018), cujo foco era mais voltado para a qualificação do processo de trabalho. Para tanto, estruturou-se em uma metodologia baseada no conceito de tutoria, que corresponde ao ato de preparar pessoas e que tinha dentro de seus objetivos desenvolver competências nos trabalhadores, incorporar mudanças e adequaçóes para a organização dos processos de trabalho, visando aprimorar a atenção, promover segurança e satisfação dos usuários, apoiando as equipes e melhorando indicadores (PARANÁ, 2015).

As tutorias eram conduzidas pelas Regionais de Saúde (RS), que correspondem à instância administrativa intermediária da Secretaria de Estado da Saúde do Paraná (SESA), e é por meio delas que o Estado exerce seu papel. Deste modo, no contexto dessa política estadual, tinham a função de apoiar os municípios nas etapas do APSUS. Uma delas seguia o referencial dos atributos da APS e utilizavase a Educação Permanente em Saúde (EPS) como estratégia de aprimoramento do processo de trabalho (PARANÁ, 2018).

Para conduzir o processo de tutoria, a SESA criou um instrumento denominado "Instrumento para Avaliação da Qualidade na APS", usualmente chamado pelos profissionais que o vivenciam na prática como "selo". O objetivo era identificar não conformidades da Unidade Básica de Saúde (UBS) e desenvolver planos de ação para correção. $\mathrm{O}$ instrumento contemplava questionamentos referentes à estrutura física e processos de trabalho da unidade para promover a aplicação dos conceitos na organização desses processos (PARANÁ, 2018). 
A avaliação das unidades de saúde foi proposta em quatro etapas do selo: bronze, que aferia o gerenciamento de riscos; prata, etapa que foi foco do presente estudo, que abordava os itens que visavam o gerenciamento dos processos e eram analisados dois grandes eixos: gestão da unidade e atributos da APS; ouro, que tinha por objetivo aferir os resultados; e diamante, que buscava assegurar a consolidação do processo de trabalho (PARANÁ, 2018).

Sabe-se da importância de processos de avaliação, qualificação e monitoramento dos serviços, e que devem ser incorporados à rotina do trabalho em saúde como forma de verificar não conformidades e nortear estratégias de ação (CARVALHO, 2012). No entanto, métodos avaliativos não esgotam ou resolvem todas as questôes do mundo do trabalho que é vivo e se produz em ato, sendo atualizado a cada encontro, mas disparam reflexóes sobre como se faz trabalho e se produz cuidado (MERHY, 2002). Para isso, é fundamental que se realize um diagnóstico situacional da realidade e que favoreça uma participação coletiva, junto aos principais responsáveis, para entender a necessidade do serviço e quais impactos a prática da padronização de processos pode acarretar (SCARTEZINI, 2009).

A avaliação e qualificação se faz como uma ação social específica, tendo como atribuição a diversidade e a subjetividade que compõe um serviço de saúde, impedindo a significação de questôes específicas sem analisar todo o contexto (DENIS; CHAMPAGNE, 1997). Por isso é importante refletir em que medida processos como esse produzem informaçôes para contribuir com tomadas de decisóes e melhoria da qualidade do cuidado prestado (CONTANDRIOPOULOS, 2006). Diante disso, o estudo buscou compreender os reflexos de um processo de qualificação da APS na rotina e no cuidado produzido pelos trabalhadores.

\section{Materiais e Método}

Esta pesquisa é resultado de uma dissertação de mestrado. Trata-se de um estudo qualitativo, exploratório, do tipo estudo de caso. O cenário foi uma Unidade de Saúde de Família (USF), localizada em um município no norte do Paraná, que aderiu ao processo de tutoria da APS e, durante a pesquisa, em 2018, estava em preparação para a certificação do Selo da Qualidade Prata. A área de abrangência compreendia uma população de cerca de 18 mil habitantes, com baixo nível socioeconômico, socialmente carentes em diversos âmbitos. Além disso, a USF, com quatro equipes de Saúde da Família (eqSF) e profissionais de outras categorias que atuavam nas 
diretrizes do Núcleo Ampliado de Saúde da Família e Atenção Básica (NASF-AB), permanece, ainda hoje, como único recurso da rede de serviços de saúde no local.

A equipe possuía constituição diferenciada, pois contava com profissionais em formação na Residência Multiprofissional em Saúde da Família de uma universidade pública da cidade que atuavam como equipe NASF-AB, e residentes de Medicina de Família e Comunidade (MFC) de um programa municipal que estavam inseridos nas eqSF, além de médicos preceptores. No período da coleta de dados, atuavam: enfermeiros, auxiliares de enfermagem, auxiliares administrativos, médicos de família e comunidade, cirurgião dentista, auxiliares de saúde bucal, funcionários de serviços gerais, Agentes Comunitários de Saúde (ACS) e uma equipe de residentes formada por enfermeiros, psicólogo, médicos, cirurgião dentista, farmacêutico, nutricionista, assistente social, fisioterapeuta e educador físico, totalizando 49 trabalhadores.

A coleta foi feita por meio de duas técnicas complementares: observaçãoparticipante e entrevistas. A escolha da observaçáo-participante deveu-se ao fato dela proporcionar maior proximidade com o objeto de estudo, permitindo explorar a realidade a ser estudada e a vivência do contexto do trabalho dos participantes da pesquisa. Na categoria de observador participante, o pesquisador tem a permissão de participar e se envolver nas atividades propostas pelo grupo estudado, mas sem se comprometer com seus valores e metas (ANGROSINO, 2009; MINAYO, 2013). Após as observaçôes foram realizadas entrevistas. Esta técnica foi escolhida por permitir alcançar informaçóes que se baseiam na própria percepção do indivíduo sobre o contexto em que vive e sobre o objeto do estudo, permitindo ao entrevistador obter informaçóes subjetivas (MINAYO, 2013).

No primeiro momento, foi estabelecida uma relação com os indivíduos do estudo por meio da observação-participante que durou aproximadamente 58 horas e contou com registros em diário de campo sobre o processo de trabalho na unidade e percepçóes da pesquisadora na vivência do campo. A observação foi realizada no período de julho a novembro de 2018 e os participantes foram todos trabalhadores da unidade daquele período, abrangendo assim, membros das quatro eqSF e do NASF-AB. Os principais espaços de observação foram momentos que permitiram o alcance do objetivo do estudo: reunióes gerais e de equipe da unidade, mutiróes para estratificaçôes de risco, reuniōes e tutoria com a coordenação da USF, juntamente com profissionais da RS responsáveis pela tutoria e com a coordenação do Programa de Saúde da Família da Diretoria de APS. 
Em um segundo momento, após ter sido realizado teste piloto com um profissional da própria unidade, foram realizadas as entrevistas com roteiro semiestruturado no período de dezembro de 2018 a abril de 2019. Com o objetivo de contemplar experiências de todas as categorias, foram entrevistados 18 trabalhadores: três enfermeiros, três ACS, um médico de MFC, dois auxiliares de enfermagem, um técnico de gestâo pública, um auxiliar de serviços gerais e um residente de diferentes categorias: um cirurgiáo dentista, um psicólogo, um nutricionista, um educador físico, um fisioterapeuta, um médico e um assistente social. Considerouse o profissional farmacêutico como perda, pois após ter sido contatado três vezes, recusou-se a participar da entrevista.

As entrevistas foram realizadas, gravadas e transcritas pela própria pesquisadora. Para preservar a identidade dos participantes, as falas foram identificadas com a letra $\mathrm{P}$ (profissionais), seguida de um número (1 a 18). As informaçôes provenientes do diário de campo e das transcriçóes foram submetidas a análise de discurso proposta por Martins e Bicudo (2005).

Para contemplar esta análise, o pesquisador realizou leituras das transcriçóes das entrevistas até que fosse possível absorver a essência do que o participante estava trazendo. Após, foram feitas leituras analíticas, com o objetivo de extrair e interpretar as Unidades de Significado (US), que correspondem a frases que tenham relação com o objetivo do estudo. Em seguida, agruparam-se as US formadas para realizar as convergências e divergências das falas, extraindo aquelas que fossem relevantes para compreender o objeto em estudo. Depois de reunir e interpretar as US emergiram duas categorias de análise, que correspondem a: "Compreensão sobre o processo de qualificação" e "Reflexos no processo de trabalho e no cuidado".

Para analisar os achados da vivência no campo, foi utilizado o autor Emerson Elias Merhy, na perspectiva da micropolítica das relaçóes e da organização do trabalho em saúde. Para o autor é fundamental a problematização dos modos de se produzir saúde tendo como plano político-metodológico a análise micropolítica do trabalho vivo em ato. Ao afirmar que o trabalho em saúde é centrado no trabalho vivo em ato, Merhy $(1997 ;$ 2002) destaca que este não pode ser totalmente baseado na lógica do trabalho morto, representado pelos equipamentos e pelo saber tecnológico estruturado, visto que este, sobretudo, se constitui em tecnologias relacionais, nos encontros das subjetividades que possuem um grau de liberdade significativo nas escolhas do modo de fazer a produção de assistência à saúde. 
Das relações que temos em todos os espaços que ocupamos, a micropolítica se faz presente. Dela se aproximam os desejos e as crenças que operam nos afetos e nas percepçóes. No campo da APS interagem trabalhadores gestores, trabalhadores da assistência, apoiadores e comunidade. Muitos desejos estão na cena, e os aspectos micropolíticos existentes estão nos momentos de negociação, de estruturação de fluxos, de tomadas de decisão, nos acordos, nas rupturas e nas fugas (FELIX, 2017).

A pesquisa foi aprovada pelo Comitê de Ética em Pesquisa Envolvendo Seres Humanos da instituição à qual está vinculada, sob número do CAAE 03471318.8.0000.5231. Para a realização da observação, foi solicitada autorização da Secretaria Municipal de Saúde e da coordenação da unidade. Para as entrevistas, todos os participantes assinaram o Termo de Consentimento Livre e Esclarecido.

\section{Resultados e Discussão}

A partir da análise dos dados, emergiram duas categorias: a primeira trata da compreensão do processo de qualificaçáo e a segunda de seus reflexos na rotina e no cuidado produzido pelos trabalhadores.

\section{Compreensão sobre o processo de qualificação}

Como resultado referente a primeira categoria, os trabalhadores pareceram compreender o processo de qualificação em duas diferentes perspectivas: como uma forma de organizar o processo de trabalho e como estratégia para captação de recursos financeiros para os municípios e interesses políticos.

O selo é uma forma da gente tentar qualificar o processo de trabalho, organizar infraestrutura, otimizar tarefas e olhar para o processo com mais atenção. (P04).

O entendimento dos trabalhadores corrobora o documento que regulamenta o programa, pois descreve que a tutoria do APSUS buscava organizar processos e desenvolver a qualidade da APS (PARANÁ, 2018). Os trabalhadores reforçaram esse processo avaliativo como uma estratégia para olhar para sua prática com mais atenção, pois com a rotina complexa, muitas vezes, não refletiam sobre as próprias ações. Refletir, planejar e avaliar o trabalho pode formar saberes para a produção de atos de saúde, pois a esfera da gestão do processo de trabalho também é constituída em espaço de cuidado (MERHY, 2004). 
Outros dizeres remetiam a esse processo como forma de obtenção de recursos financeiros para os municípios e como campanha político-partidária.

É uma forma de tentar obter mais verba para o município e as UBS. Existe também o objetivo de usar o selo como campanha futura ou de tentar conseguir um cargo político utilizando as açóes que foram implementadas pelo selo. (P01).

Como no contexto nacional havia o PMAQ, um processo de avaliação com repasse financeiro direto às equipes, alguns trabalhadores, por vezes, confundiam os processos associando o APSUS a obtenção de recursos. O APSUS é um programa de qualificação em que o Estado repassa uma verba mensal para os municípios (PARANÁ, 2018), assim aportando recursos financeiros para a APS do município como um todo e náo diretamente para as unidades.

Já sobre o uso do programa como forma de destaque político, sabe-se que tais práticas costumam ser recorrentes no cenário político brasileiro. Quando os interesses político-partidários se sobrepóem aos objetivos de qualificação da APS existem grandes riscos de descontinuidade desses processos impactando diretamente no cotidiano dos profissionais de saúde, pois precisam reestruturar-se a partir de outra norma, interferindo na qualidade do atendimento à população assistida.

Acredita-se que um programa de governo traz consigo questôes amplas de uma macropolítica sendo colocada em ação e, para isso, são criados protocolos, leis, normas e regulamentos. Estes entram no rol das tecnologias leve-duras que são utilizadas para operar o trabalho em saúde (MERHY, FRANCO, 2003). Entretanto, sendo o trabalho vivo, é na rotina dos trabalhadores que a norma é operada e a macropolítica impacta na micropolítica, em uma via de mão dupla (FELIX, 2017).

Esse cenário evidenciou a macropolítica operando na micropolítica, de forma que o cuidado produzido precisou ser desviado para que a macro pudesse ter espaço para acontecer, numa tentativa de capturar a capacidade criativa do trabalhador. Contudo, mesmo que ocorressem tentativas de estipular uma padronização para as açôes e que existissem diferentes lógicas de operar no cotidiano do trabalho em saúde, os profissionais encontraram possibilidades de desdobramentos, de modo a refletir e problematizar sobre o contexto local (MERHY, 1997; MALTA; MERHY, 2003).

\section{Reflexos no processo de trabalho e no cuidado}

O processo de certificação do selo prata afetou o dinamismo de trabalho e a produção do cuidado da unidade em estudo. Um dos reflexos mais relatados 
pelos participantes foi a sobrecarga de trabalho e o desgaste emocional atribuídos principalmente ao cumprimento do prazo, obrigatoriedade de tarefas e a falta de significado na realidade dos trabalhadores.

Para mim o selo significou um desgaste físico e mental muito grande. É muita pressão para um período curto de tempo. Eu acho que as ACS e a enfermagem estavam mais sobrecarregadas. (P14).

O prazo e a quantidade de atividades exigidas pelo selo eram fatores de desgaste emocional muito grande para os trabalhadores. Mota e David (2015), em estudo sobre problematizações do PMAQ, também questionaram o estímulo por relaçôes competitivas para o reconhecimento por mérito e de que forma isso caminha na direção contrária a uma saúde que visa o cuidado integral. Os trabalhadores demonstraram insatisfação com o prazo, pois, além de intensificar o sentimento de obrigatoriedade, a equipe se preparava para o momento da avaliação do programa em si, dificultando a busca pela melhoria da qualidade. A macropolítica atravessava e disputava espaço com outras atividades desenvolvidas pelos servidores.

Leite (2015) reflete o quanto as instituiçôes públicas têm incorporado a lógica capitalista e da produtividade. Ao atender essas características, a equipe se insere em um fluxo de acentuada competitividade, trabalhando por meio de metas e, sem perceber, deixa-se capturar pelo processo, perdendo a identidade do seu fazer profissional. Por mais que haja a tentativa de emancipá-los desse processo ao qual são submetidos, a baixa remuneração, a falta de recursos humanos, o território em que se encontram e o próprio processo de trabalho dificultam a libertação dessa condição de oprimidos.

A pressão pelo resultado e a exigência de tarefas avaliativas podem contribuir para a exaustão e desgaste psíquico de toda a equipe de saúde (MOTA; DAVID, 2015). Os entrevistados enfatizaram que se fosse um processo menos verticalizado, se o empenho tivesse ênfase no cuidado e não na conquista do selo, se preocupariam menos com o prazo e, assim, seria um trabalho que pudesse continuar além da produção de dados. Isso evidencia o quanto o controle normativo e prescritivo da macropolítica sobrepôs as demandas da micropolítica. No entanto, a gestão do trabalho não deve ser entendida apenas sob essa ótica, mas reconhecer que cada profissional é sujeito-do-trabalho e desenha a organização do seu próprio processo produtivo (FRANCO, 2013). 
Outro reflexo relacionado a sobrecarga física e mental dos trabalhadores dizia respeito a forma de avaliação do programa, pois em muitos momentos sentiam-se pressionados a realizar algumas atividades apenas para alcançarem as exigências do instrumento. Sentiam-se frustrados e desamparados pela gestão, pois a participação no processo do selo evidenciava problemas de recursos humanos e materiais, mas não possuíam recursos para a solução.

Embora o processo de tutoria tenha se feito presente e tenha apresentado um caráter aberto e flexível, apresentou algumas limitaçôes, considerando que nem todos os trabalhadores da USF participavam do processo, ficando restrito somente à gestão da unidade. Com isso, determinadas questôes e necessidades trazidas à tona nem sempre eram debatidas, o que pode ter influenciado na resolução de algumas demandas, como esta apresentada:

A unidade precisa lixo. Ao invés de ser sincera e dizer que não tem lixo, empresta de outra UBS [...]. Para quê fazer essa maquiagem? Tem que mostrar o que não temos, pois o município tem que dar conta, o Estado tem que dar conta. (P02).

Saddi et al (2018), em estudo a respeito do PMAQ, chamam isso de "jogos de trapaça”, principalmente em contextos com baixa capacidade organizacional e baixo capital para custear as necessidades locais, gerando falsos resultados, falsos indicadores de saúde e prejudicando a gestão da unidade. Salci et al. (2019) também identificaram que a forma como ocorrem processos avaliativos compromete a prática assistencial. Essa obrigação em realizar as funçóes além da capacidade leva os profissionais a vivenciarem um sentimento de opressão ocasionado pelo círculo vicioso: condições de trabalho deficientes, falta de recursos que condicionam as relaçôes de produção e estímulo a trapaça para alcançar a meta proposta.

Fica evidente a incoerência de um modelo de avaliação quantitativo e pontual no que se refere a melhorias da qualidade do serviço. Estudos apontam uma outra opção avaliativa, como metodologias qualitativas, que ajudam a perceber a singularidade do local e prática profissional (SALCI et al., 2019; ARRUDA; BOSI, 2017). Processos avaliativos devem passar pela aceitaçâo dos principais atores envolvidos de modo que compreendam sua importância e incorporem práticas eficientes em seu contexto de atuação.

Programas avaliativos quantitativos e prescritivos podem não provocar novos sentidos de práticas que impactam no processo de trabalho. Discordar das questóes solicitadas, investigar lacunas e estabelecer diálogo para problematizar a realidade 
deve ser prioridade tanto para a equipe da unidade, quanto para a equipe gestora junto à tutoria do programa.

Alguns trabalhadores entendiam o selo como uma estratificação de risco, pois dentre as açôes esta foi a que mais demandou aumento de carga de trabalho. As estratificaçóes de risco eram consideradas macroprocessos necessárias a serem executadas pelos trabalhadores e suas implantaçóes estavam inseridas no Modelo de Atenção à Condições Crônicas (MACC), ao qual o APSUS está vinculado. Constituíam um elemento fundamental no MACC ao dividir a população total em subpopulaçôes, segundos os riscos, disparando uma série de açôes, estratégias de intervenção, tecnologia de gestão da clínica e cuidado profissional, elaborados a partir de protocolos pré-estabelecidos para o manejo das condiçóes crônicas (PARANÁ, 2018; MENDES, 2011; 2018). Percebeu-se que, o que era para ser um mecanismo do processo (estratificaçáa), se tornou um conceito para alguns trabalhadores, pois eles podem ter compreendido o sentido do selo a partir daquilo que operavam no trabalho.

Sabe-se que, com a transição epidemiológica, condiçôes como diabetes e hipertensão são importantes agravos que acometem a população em geral. Entretanto, as análises feitas pelos profissionais eram que o instrumento não se preocupava com a singularidade do território. Afirmaram que, apesar da alta prevalência desses agravos, outras questóes relacionadas à vulnerabilidade da população em relação à violência, condiçôes sociais e escassos recursos de apoio no território não eram enfatizadas.

É um tiro no pé. Totalmente inválido para a nossa realidade. Ficar pensando em estratificar hipertenso e diabético enquanto as pessoas não têm nem o que comer. (P07).

O objetivo do processo de qualificação na teoria, mostra-se como um processo de diálogo, de apoio e ferramenta para mudanças no trabalho (PARANÁ, 2018). Entretanto, é possível perceber que o conteúdo proposto pelo instrumento estava distante da prática profissional e muitas vezes não fazia sentido para aquela unidade de saúde, para a população abrangente e para a conduta profissional.

Não pode existir um conhecimento construtivo alheio à realidade dos trabalhadores. Logo, mostra-se a importância da leitura de mundo, do local de trabalho, da práxis e que esta não pode ser feita a partir de apenas um olhar, mas sim a partir de todos que fazem parte do processo de aprendizagem. Ora, educar para transformar pressupóe análise da realidade dos trabalhadores e sua problematização (FREIRE, 2015). 
Não se transforma o que não se conhece e, na lógica da EPS, educar para transformar exige coerência com os objetivos do programa de qualificação(FREIRE, 2015). Tentar implementar um processo da mesma maneira para todo o Estado é uma forma verticalizada de padronizar as práticas dos trabalhadores. Por outro lado, é indispensável que as palavras de quem vive aquela realidade sejam ouvidas e estejam presentes no processo de transformação, pois é a partir da compreensão crítica da realidade que os servidores são capacitados para transformar a si e a seu contexto (ANTUNES, 2018).

Outro reflexo mencionado refere-se a ênfase que se deu à gestão do processo de certificação em detrimento da assistência. Sabe-se que gerenciar também é cuidar, porém, mencionaram que a fragmentação gerada pelos diversos instrumentos de estratificação determinou deslocamento do cuidado para tarefas burocráticas que sobrecarregavam os trabalhadores e pouco acrescentavam na assistência. Logo, percebeu-se que o mecanismo da estratificação de risco pareceu ser o ponto mais crítico na compreensão dos participantes por ser muito normativo e de aplicabilidade biomédica.

Outra coisa absurda é essa escala de saúde mental. Só por você morar nesse bairro você já é alto risco. Porque tem: "você está exposto a violência?" Sim. "Vulnerável social?" Sim. "O Estado está amparando o lugar onde você vive?” Não. "Você já presenciou alguma vez violência ou abuso de álcool e drogas?” Sim. "Foi desamparado na infância?” Sim. Pronto! Alto risco. Concordar com essas escalas era uma dificuldade muito grande. A gente tinha que aceitar, colocar na planilha, fragmentar o cuidado e dar conta de atender toda a agenda, mas eu buscava prezar pela qualidade do atendimento. (P12).

Além disso, após fazerem essas estratificaçóes, era necessário agendar as consultas de acordo com o risco do paciente, baseando-se na linha guia ${ }^{1}$ da SESA, como também era necessário aplicar algumas escalas de cuidado nas consultas e visitas aos pacientes. As críticas diziam que as estratificaçôes, em geral, não eram pertinentes e que o excesso de consultas programadas, muitas vezes desnecessárias, dificultava o acesso para os demais usuários do serviço.

A agenda fica cheia de retorno programado. $\mathrm{O}$ paciente que vem na unidade não consegue entrar na agenda, fica para daqui não sei quantos meses. Se ele for diabético, hipertenso, idoso etc., ele tem prioridade e consegue passar todo mês, agora se ele não for nada disso ele é jogado lá para a frente. (P12).

O foco na gestão de processos burocráticos também prejudicou açôes no território, como a perda da qualidade e quantidade das visitas domiciliares realizadas 
pelos ACS em função da intensificação da produção de cadastros das famílias e cancelamento de visitas realizadas por outros profissionais para a organização de planilhas e prontuários.

A gente fica muito em cima disso e não consegue sair para conhecer esse paciente. Eu estratifiquei dezenas de prontuários, mas eu não conheço esses pacientes, eu não sei qual que é as histórias deles. (P04)

A partir desses resultados, ficou evidente a centralidade das açóes no processo avaliativo em responder as determinaçôes do "selo" e não diretamente no cuidado e necessidade do usuário. Diante do processo de avaliação, ocorreu uma disputa entre as práticas assistenciais e burocráticas com o intuito de atingir a meta estabelecida pelo programa. Ambos são importantes, entretanto, é essencial que haja um equilíbrio e não exclusão de um deles, pois questóes importantes como o acesso e práticas assistenciais ficaram prejudicadas. Essa é a disputa entre a intencionalidade do projeto de cuidado no sentido do encontro, do vínculo, processos relacionais e autonomia dos profissionais para agir da maneira como lhes parece correta com o projeto de normas e instrumentos gerenciais (BADUY, 2010). Nenhum escopo de perguntas e linha guia são capazes de entender a complexidade da vida e a subjetividade de cada encontro.

Diante de todo esforço em corresponder às expectativas do programa, cabe refletir se o paciente é colocado como centro do cuidado, o quanto este é central nas experiências de trabalho e nas discussóes e qual lugar ele ocupa. A maior parte do tempo busca-se resolver e falar sobre processos burocráticos e minimamente o cuidado é pauta das relaçóes comunicativas. O que poderia mudar nas pautas dos processos comunicativos para produzir cuidado? (MERHY, 2019).

Cecílio (2011) destaca as múltiplas dimensóes da gestão do cuidado em saúde e provoca-nos a pensar sobre a dificuldade de processos avaliativos. Como qualificar um processo de trabalho e fazer gestáo do cuidado a partir de um único instrumento, sendo que este precisa ser capaz de abranger diferentes dimensóes na saúde? Como padronizar os indivíduos em um escopo de doenças e cuidados? E como avaliar, por meio de um instrumento objetivo, campos tão heterogêneos, singulares e complexos? $\mathrm{O}$ autor ainda faz refletir sobre o papel externo de gestores e suas tentativas de normalizar e controlar o aspecto micropolítico, no qual os principais sujeitos carregam valores, interesses e sentidos para o trabalho em saúde. Portanto, cabe minimizar a ideia de que a avaliação da micropolítica se faz a partir de indicadores externos, estruturados pela macropolítica. Ora, seguir essa lógica acarreta aos 
trabalhadores realizar uma tarefa árdua de produção de dados e informaçôes que, muitas vezes, não é coerente com quem cuida e é cuidado.

Nesse contexto, a EPS pode se mostrar como uma alternativa em direção a um cuidado mais integral, sendo uma oportunidade de viver as relaçôes produzidas a partir do mundo do trabalho, de maneira horizontal, baseando-se nas trocas de experiências e diálogos (CARVALHO, MERHY, SOUSA, 2019). A proposta do selo vem atender os objetivos do programa e acaba interferindo no protagonismo dos trabalhadores no próprio processo de qualificação de seu trabalho, tendo que desenvolver, a todo tempo, momentos de EPS como linha de fuga da verticalização do processo.

Destaca-se que as falas apresentadas até o momento foram as mais evidenciadas nas entrevistas, porém não necessariamente mostraram-se como a única realidade exposta pelos entrevistados. Embora tenham sido identificadas fragilidades em relação à percepção do processo de qualificação, também foi evidenciada potencialidade.

Um reflexo positivo do processo de qualificação foi a oportunidade de repensarem sua prática profissional e perceberem os problemas presentes no processo de trabalho, avaliarem sua atuaçáo, problematizarem na tentativa de encontrar um significado para sua realidade e buscarem possíveis mudanças para alcançar maior qualidade no cuidado ofertado.

Talvez nunca se pensasse sobre o processo de trabalho e viu que esse modelo que o selo traz é um modelo complicado, mas pelo menos é um momento de se pensar como a gente faz, como deveria ser, o que a gente pode melhorar. (P12).

O contraditório se fez presente, ora insatisfeitos, ora colocando-se em análise. A reflexão sobre o processo de trabalho permeou a prática dos trabalhadores, que começaram a pensar a respeito da forma como a certificação era conduzida. A ênfase nos processos burocráticos em detrimento do processo assistencial, por exemplo, foi evidenciada pela equipe de modo que houve um movimento de resgate às práticas assistenciais.

A equipe de saúde, mesmo capturada pela imposição de metas e uma lógica tradicional de processo educativo, que dificultava a capacidade de reflexão, criou espaços de diálogo por meio da formação de seus próprios arranjos, movida, sobretudo, pela equipe de residência, que influenciava toda a equipe.

Faz parte do trabalho em saúde e da EPS percorrer o caminho de refletir sobre as práticas de trabalho e encontrar possíveis soluçôes de problemas (MERHY, FEUERWERKER, CECCIM, 2006). Portanto, a discussão da equipe possibilitou 
uma renormalização do processo de trabalho com foco nas necessidades do usuário. Por meio da problematização e diálogo entre os profissionais, foi feita uma leitura das questôes avaliadas no programa que culminaram em perceber os produtos imediatos das atividades propostas pelo selo, os impactos dessas intervençóes e a adequação à realidade assistencial.

\section{Considerações finais}

Os principais reflexos referentes ao processo de qualificação da APS na organização do trabalho e do cuidado produzido, referiram-se à valorização de processos burocráticos em detrimento do cuidado, ao grande desgaste físico e mental dos profissionais e à aplicação do processo de avaliação quantitativo e prescritivo que náo foi capaz de olhar para o subjetivo, para as peculiaridades da unidade de saúde, da populaçáo assistida e dos profissionais. É importante pensar em como o programa de qualificação aconteceu tal qual um processo macropolítico verticalizado e o quanto pode impactar na micropolítica, especialmente na dinâmica do trabalho e no cuidado prestado.

A EPS mostrou-se uma importante ferramenta adotada no processo de trabalho, principalmente no que se referiu à problematização das questôes levantadas pelo selo. Apesar do processo de certificação ser repleto de orientaçôes prescritivas, a equipe de saúde deu novos significados às atribuiçôes. Mesmo que não fosse possível colocar alguns aspectos em prática, o fato de refletir sobre o processo de trabalho pode gerar oportunidades de modificar o cuidado prestado, como uma forma da micropolítica operar a macropolítica e encontrar seu modo de acontecer.

Esses espaços de EPS podem ter sido impulsionados pela existência da Residência na USF, que contribuiu fortemente para as reflexôes e problematizaçôes a respeito do processo de trabalho, evidenciando a potência da aproximação do ensino com o serviço. Embora isso seja um fator importante para fomentar o cuidado e as reflexôes no processo de qualificação da APS, mostrou-se também como uma limitação do estudo, pois outras unidades inseridas no processo de certificação do selo no Estado não tiveram essa contribuição e poderiam apresentar resultados diferentes desse estudo.

O processo de observação-participante foi fundamental para dar suporte às reflexôes feitas nesse artigo. As entrevistas mostraram-se um potente recurso para 
captar a percepção dos profissionais acerca do processo, porém a observação permitiu ao pesquisador adentrar a realidade dos profissionais e perceber como o processo do selo se estabelecia no dia a dia dos trabalhadores. ${ }^{2}$

\section{Referências}

ANGROSINO, M. Etnografia e observação participante. Porto Alegre: Artmed, 2009.

ANTUNES, A. B. Educar para transformar. In: SEMANA PAULO FREIRE ONLINE. 50 anos da Pedagogia do Oprimido. Local: Instituto Paulo Freire, 2018.

ARRUDA, C. A. M.; BOSI, M. L. M. Satisfação de usuários da atenção primária à saúde: um estudo qualitativo no Nordeste do Brasil. Interface, v. 21, n. 61, p. 321-332, 2017.

BADUY, R. S. Gestão municipal e produção do cuidado: encontros e singularidades em permanente movimento. 2010. 191 f. Tese (Doutorado em Clínica Médica) - Faculdade de Medicina, Universidade Federal do Rio de Janeiro, Rio de Janeiro. 2010.

CARVALHO, A. L. B et al. A gestão do SUS e as práticas de monitoramento e avaliação: possibilidades e desafios para a construção de uma agenda estratégica. Ciência e saúde coletiva, Rio de Janeiro, v.17, n.4, p. 901-911, abril, 2012.

CARVALHO, M. S.; MERHY, E. E; SOUSA, M. F. Repensando as políticas de Saúde no Brasil: Educação Permanente em Saúde centrada no encontro e no saber da experiência. Interface, v. 23, e190211, 2019.

CECILIO, L. C. O. Apontamentos teórico-conceituais sobre processos avaliativos considerando as múltiplas dimensóes da gestão do cuidado em saúde. Interface, v. 15, n. 37, p. 589-599, 2011. CONTANDRIOPOULOS, A. P. Avaliando a institucionalização da avaliação. Ciência e Saúde Coletiva, v. 11, n. 3, p. 705-711, 2006.

DENIS, J. L.; CHAMPAGNE, F. Análise de Implantação. In: HARTZ, Z. M. A. (Orgs.). Avaliação em Saúde: dos modelos conceituais à prática na análise da implantação de programas. Rio de Janeiro: Editora FIOCRUZ, 1997. 132 p.

FÉLIX, S. B. C. M. Momentos e movimentos da implantação de um Núcleo de Apoio à Saúde da Família (NASF) em uma cidade do sul do Brasil. 2017. 172f. Tese (Doutorado em Saúde Coletiva) - Universidade Estadual de Londrina, Londrina. 2017.

FRANCO, T. B. O trabalhador de saúde como potência: ensaio sobre a gestão do trabalho. In: FRANCO, T. B.; MERHY, E. E. Trabalho, produção do cuidado e subjetividade em saúde. São Paulo: Hucitec, 2013.

FREIRE, P. Pedagogia do Oprimido. 59. ed. Rio de Janeiro: Paz e Terra, 2015. 
LEITE, J. L. Produtivismo acadêmico e adoecimento docente: duas faces da mesma moeda. In: FERREIRA, A. et al. (Orgs.). Precarizaçâo do Trabalho e Saúde Docente nas Universidades Públicas Brasileiras. Fortaleza: EdUECE, 2015. p. 72-79.

MALTA, D. C.; MERHY, E. E. A micropolítica do processo de trabalho em saúde: revendo alguns conceitos. Revista Mineira de Enfermagem, v. 7, n. 1, p. 61-66, 2003.

MALTA, D.C et al. Family Health Strategy Coverage in Brazil, according to the National Health Survey, 2013. Ciência e Saúde Coletiva, Rio de Janeiro, v. 21, n.2, p.327-330, fevereiro, 2016.

MARTINS, J.; BICUDO, M. A. V. A pesquisa qualitativa em psicologia: fundamentos e recursos básicos. São Paulo: Centauro, 2005.

MENDES, E. V. As redes de atenção à saúde. 2. ed. Brasília: Organização Pan-Americana da Saúde, 2011. 549 p.

MENDES, E. V. O cuidado das condições crônicas na atenção primária à saúde. Revista Brasileira em Promoção da Saúde, v. 31, n. 2, p. 1-3, 2018.

MERHY, E. E. Dispositivos de gestão hospitalar: fortalecendo os hospitais e as redes de cuidado. In: Multidão de EUS: o cuidado da vida e os movimentos de resistência. Londrina, 2019.

. Em busca do tempo perdido: a micropolítica do trabalho vivo em saúde. In: MERHY, E. E.; ONOCKO, R. (Orgs.). Agir em saúde: um desafio para o público. São Paulo: Hucitec, 1997. O ato de cuidar: a alma dos serviços de saúde. In: BRASIL. Ministério da Saúde. Secretaria de Gestão do Trabalho e da Educação na Saúde. Departamento de Gestão e Educação na Saúde. Ver - SUS Brasil: cadernos de textos. Brasília: Ministério da Saúde, p.108-137, 2004. . Saúde: a cartografia do trabalho vivo. 3.ed. São Paulo: Hucitec; 2002.

MERHY, E. E.; FEUERWERKER, L. C. M.; CECCIM, R. B. Educación Permanente en Salud: una Estrategia para Intervenir en la Micropolítica del Trabajo en Salud. Salud Colectiva, v. 2, n. 2, p. 147-160, 2006.

MERHY, E. E.; FRANCO, T. B. Por uma Composição Técnica do Trabalho Centrada nas Tecnologias Leves e no Campo Relacional. Saúde em Debate, v. 27, n. 65, p. 316 - 323, 2003.

MINAYO, M. C. S. O desafio do conhecimento: pesquisa qualitativa em saúde. 13. ed. São Paulo: Hucitec, 2013.

MOTA, R. R. A.; DAVID, H. M. S. L. Programa Nacional de Melhoria do Acesso e da Qualidade da Atenção Básica: questôes a problematizar. Revista Enfermagem UERJ, v. 23., n. 10, p. $122-127,2015$.

PARANÁ. Secretaria de Estado da Saúde do Paraná. A tutoria na APS. Curitiba: Secretaria de Saúde, 2018. Disponível em: http:/www.saude.pr.gov.br/arquivos/File/ CadernaATutorianaAPS_2018.pdf 
. Secretaria de Estado da Saúde do Paraná. Cartilha tutoria. Curitiba: 2015. Disponível em: http://www.saude.pr.gov.br/arquivos/File/CartilhaTutoria2015.pdf

SADDI, F. C. et al. Perceptions and evaluations of front-line health workers regarding the Brazilian National Program for Improving Access and Quality to Primary Care (PMAQ): a mixed-method approach. Cadernos de Saúde Pública, v. 34, n. 10, 2018.

SALCI, M. A. et al. O programa de avaliação da atenção básica na ótica dos profissionais de saúde e gestores. Revista da Rede de Enfermagem do Nordeste, v. 20, n. 1, 2019.

SCARTEZINI, L. M. B. Análise e melhorias de processos. 2009. Disponível em: <http://siseb. sp.gov.br/arqs/GE\%20B\%20-\%20An\%C3\%A1lise-e-Melhoria-de-Processos.pdf>. Acesso em: 27 nov. 2019.

SILVA, L. M. V. Avaliação de políticas e programas de saúde. Rio de Janeiro: Editora Fiocruz, 2014.

\section{Notas}

${ }^{1}$ Linha guia refere-se ao instrumento adotado pelo Estado que determina gestão e ação para cada condição de saúde nos diferentes pontos de atençáo à saúde, como um protocolo que norteia o trabalho. A gestáo da condição de saúde estrutura-se em quatro grandes componentes: o plano de cuidado, a gestáo dos riscos da atenção à saúde, as mudanças de comportamento de profissionais de saúde e de pessoas usuárias e a programação da atenção à saúde (MENDES, 2011).

${ }^{2}$ M. L. Beraldi: pesquisa, metodologia, concepção, redação e revisão do artigo. F. de F. Mendonça: concepção, redação e revisão do artigo. B. G. Carvalho e S. B. C. M. Félix: redação e revisão do artigo. 


\section{Abstract}

Reflections of a qualification process of

Primary Health Care in the routine and care provided by its workers

An exploratory, qualitative research, case study

type, that aimed to comprehend the reflections of a qualification process of the Primary Health Care in the work process and in the health care offered. Data were collected from July of 2018 to April of 2019, using the observation-participant study tool and semistructed interviews with health workers of Family Health Unit. The results pointed out the work process organization, physical and mental overload, emphasis on bureaucratic issues in detriment of patient care, difficulties in the process of considering the territory uniqueness. Nevertheless, it provided the opportunity to reflect over the professional practice. Vertical and out of context processes hamper the understanding of the reality and because of that the practice of continuing health education is important so it can give space for dialog and problematize the experiences lived to suit the macro-politics to the local reality.

> Keywords: Primary Health Care; interprofessional relations; health assessment; Permanent Health Education. 